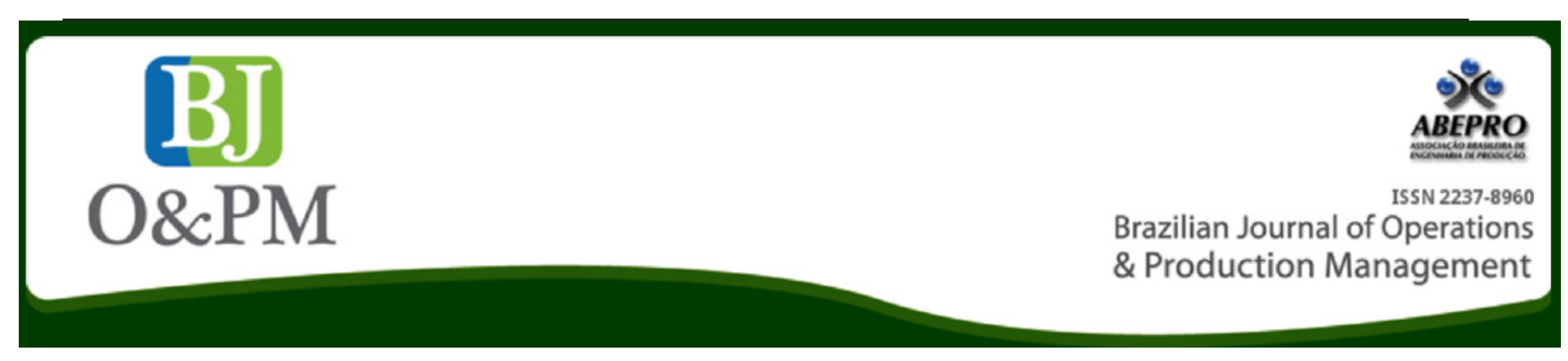

\title{
INCURSION OF KNOWLEDGE MANAGEMENT IN MANAGEMENT EXCELLENCE AWARDS: AN ANALYSIS IN THE LATIN-AMERICAN CONTEXT
}

\author{
Pedro Carlos Resende Junior ${ }^{a}$; André Luiz Nascimento Reis ${ }^{b}$ \\ ${ }^{a}$ University of Brasilia (UnB) - Brasilia, BR, Brazil; \\ ${ }^{b}$ Catholic University of Brasilia (UCB) - Brasilia, BR, Brazil;
}

\section{ABSTRACT}

Purpose - The aim of this article is to describe the relationship between theoretical knowledge management assumptions and knowledge management process involving Models and Awards for Management Excellence in Latin America.

Design/methodology/approach - Relevant literature was reviewed by carrying out a survey based on document analysis involving requirement of models and awards for excellence in management in the following countries: Argentina, Brazil, Chile, Colombia and Mexico. This research study used qualitative data-collecting methods by means of a content analysis technique, carried out between February 2013 and December 2014. The corpus was treated by using a content analysis technique, where categories of analysis were codified based on criteria, items and management process requirements of the models investigated.

Findings - The findings show that the mains theoretical knowledge management assumptions are present, in some degree, in models of management excellence in Latin America, but highlight the fact that these models present different structure and maturity levels, some of which combine knowledge management with strategic perspectives and innovation management.

Research limitations/implications - The research used qualitative methods of data collection through documentary analysis, conducted 2013 and 2014. As future research agenda, it is recommended to extend the survey to other countries in Latin America.

Practical implications - The alignment obtained from the consistency of analysis allowed to find a pattern followed by Latin America countries in the models and management excellence awards.

Originality/value - This survey made it possible to produce consistent analyses based on pre-existing models that consider knowledge management as the basis of organization and brought methodological contributions for the management area.

Keywords: knowledge management, management models, excellence awards, Latin America. 


\section{INTRODUCTION}

This article aims to describe the presence of knowledge management theoretical assumptions and the process of knowledge management in Management Excellence Models and Awards in Latin America. This research makes it possible to produce consistent analyses based on preexisting models that consider knowledge management as the basis of organization.

Six models and awards for management excellence where selected for this research study. The countries and their respective models are as follows: a) Argentina - Model for Management Excellence in Companies (MECA, 2013); b) Brazil - Management Excellence Model (FNQ, 2014); c) Brazil - Model for Management Excellence in Public Services (Gespública, 2014); d) Chile-Management Excellence Model (MEMC, 2012); e) Colombia - Model for the Colombian Quality Management Award (PCC, 2014); and, f) México Model for National Competitiveness, Medium-size and large Companies (PNC, 2013).

Two models were selected in the case of Brazil: the Management Excellence Model and the Model for Management Excellence in Public Services. The first model has been coordinated since 1992 by the Brazilian National Foundation of Quality, while the second, which has been coordinated since 1998 by the Ministry of Planning, focuses exclusively on public sector organization with the spheres of federal, state and municipal governments. The latter model, also called Gespública, adheres to current New Public Management, and their keywords are: active professional management; performance standards and indicators; greater emphasis on results controls; the trend towards greater internal productivity and outside competition; imitating styles of management used in the private sector; greater emphasis on discipline and parsimony in resource use.

According to Hood (1991), there was a tendency in government administration to use New Public Management in an effort to reverse the growth of the administrative sector and to develop an international 'agenda' that was more centered on general aspect of public administration.

The problem situation hereby presented is that, although such models appear to have a similar structure, these show differences in infrastructure, management process requirements and scales of evaluation that, for the purpose of this research, need to be normalized, so that a comparative evaluation of their knowledge management construct can be carried out, bearing in mind their strong points and lacunae as well as theoretical references.

The normalizing process consists to transform all the requirements of selected models in assertive descriptions with unique clear, observable and measurable actions. Thus, it is possible to adopt a single rating scale from the various scales present in the selected management models.

\section{THEORETICAL REFERENCES}

According to Barclay et Murray (1997), information and knowledge are recognized as corporative assets and, as such, their management requires policies, strategies and tools. Furthermore, according to those authors, since those assets produce competitive advantages, they require systemized search and transfer mechanisms for the stakeholders. As stated by Nonaka (2008), those organizations that are able to continually create and spread knowledge are those that have the greatest strategic success.

When reviewing literature as part of this investigation, a recurring question that arose through these journals and in the selected management models was how to carry out knowledge management. Accordant to Bukowitz (2002), "... knowledge management is a process by which an organization produces wealth, based on its knowledge or intellectual capital". Since wealth is derived from knowledge that is used to create effective procedures and value management for clients, including organizational innovation, in products and services given to the clients.

Sveiby (2001) also views knowledge management as the art of creating value based on intangible assets, where knowledge is like a human feature. In the same vein, Broadbent (1997) states that information management is much more than just organizing data and carrying out research, as well as a series of information management practices and organizational learning. Dalkir (2005) also shares this interdisciplinary viewpoint that knowledge management involves strategies, tools and skills.

On the other hand, Davenport (1998) establishes a direct relationship between information and knowledge when he defines knowledge as information combined with context, experience, interpretation and reflections. This same author also adds that organizations are more careful about how to create, transfer and efficiently use the knowledge generated. The combination of these three activities is known as knowledge management. In the same vein, most of the models selected for the purpose of this research, adopt criteria of excellence aimed at knowledge management involving integrated, though distinct information management and knowledge management practices.

Contradictory to the previous definitions, Earl et Scott (1999) state that there is no widely accepted definition about the construct of knowledge management. Even so, these authors mention three points of convergence: a) that knowledge is a sustainable source of competitive advantage; b) that, in general, organizations acknowledge that they 
do not administer knowledge well; e) that organizations recognize the potential of knowledge value creation, but that this is something they do not adequately explore. Even though they do not acknowledge that there is a widely accepted definition of knowledge management, the points hereby illustrated refer to common elements highlighted by the afore-mentioned authors.

In a study involving 160 models of knowledge management frameworks from around the world, Heisig (2009) noted that, in general, these models show that the following activities are an inherent part of knowledge management: to identify, create, store, share and apply. To a greater or lesser degree, in case of the Latin American models of management excellence studied in the present research work, from the perspective of a knowledge management phenomenon, regard these as macro processes.

In the case of the definitions used by the two main awards for management excellence in Brazil, Gespública (2014) identified knowledge management as an "approach aimed at identifying, registering, developing, disseminating and controlling knowledge in an organizational environment", there being a lacuna in direct relationship to the generation of activities for the organization. The same does not occur in the case of the Brazilian National Quality Foundation - FNQ (2007), which defines knowledge as: a systematic and intentional process in line with the strategy that aims to generate, preserve and share organizational knowledge, in order to increase tangible and intangible assets", which highlights strategic alignment in knowledge management.

For the purpose of this research, knowledge management is considered as a structured process to manage intangible assets that involve such activities as sharing, creating, applying, storing and identification, so as to generate new assets and wealth for organizations.

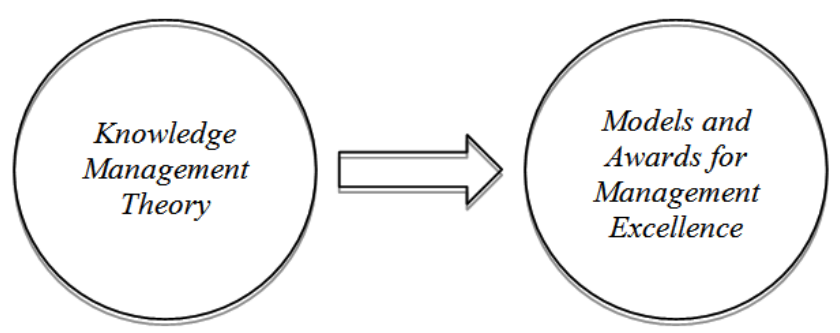

Figure 1. Knowledge Management Theory in Models and Awards for Management Excellence.

Source: The authors own

\section{METHODOLOGY}

The present research study was undertaken using a qualitative approach for data collection and analysis. A literature review was conducted, using articles published in national and international journals, books and papers published in congress annals. Contact was also maintained with researchers and specialists who act as evaluators of excellence management models, as well as organizational management researchers belonging to universities' research groups. Altogether 12 structured interviews were conducted.

The document analysis and content analysis were undertaken between February 2013 and December 2014, which consisted of a survey based on data that involved excellence management models and excellence awards in the following countries: Argentina, Brazil, Chile, Colombia and Mexico. The corpus was treated by means of a content analysis method, according to Bardin (2002), where analysis categories were codified based on the criteria, items and management process requirements of the models investigated.

A priori categories were created following the method used to select the models, by organizing message elements that share common characteristics, thereby guaranteeing their mutual exclusion, when data does not belong to more than one category, when the relevance of the categories meet the issues and objectivity proposed by this research study, based on a summarized description of the elements related to each category.

Category 1, called Information, deals with management process requirements, management practices and standards of work and measurement mechanisms related to the need for information, information systems management and the integration of information between organizations and stakeholders, with their respective information security management. Category 2, called Knowledge, presents extracts related to the development, retention, protection, dissemination and use of knowledge that an organization needs to carry out its operations and strategies.

\section{DATA ANALYSIS}

The six management excellence awards and models investigated in this research study consist of principles and criteria that embody management process requirements for world-class organizations that propose to make use of these. Generally speaking, the evaluation process for each award takes place in three stages: a) through an individual and consensual analysis; b) a visit to the organizations concerned; c) selection of the organizations to be recognized and given an award.

Once the organizations who are candidates have submitted a management report for the respective awards, evaluation boards of specialists are formed to carry out individual and consensual assessments. At this stage, the organizations with the highest ratings qualify for the second stage of the process, when they are paid a visit by the Examining Board who can verify, in situ, the management 
practices and outcomes identified by the Evaluation Board. At this stage, the points given to an organization may be changed, increased or decreased, depending on what is observed during the visit. After each visit, the Senior Examiner from each board presents the final results to a Board of Judges, the technical body with the greatest authority within each model. Finally, the board of judges evaluates the Assessment Report prepared by the examining board and indicates which organizations are eligible for consideration, the organization with the best performance is then recommended for an award for the model in question.

The organization has to present, in the case of all models, and every requirement, a description of the management practice that meets the requirements, the area responsible, how frequently this practice occurs, the standards of work and control methods that ensure these practices are carried out.

\subsection{Model for Management Excellence in Companies - Argentina}

Among its nine principles, the model from Argentina includes none that is solely dedicated to the construct of knowledge management, although in Criterion 6: Management of Resources, there is one item that deals specifically with this subject, called Information and Knowledge Management.

According to MECA (2013), the administrative processes for management knowledge aim to evaluate the practices and methodologies that organizations use to manage information and knowledge so as to make decision and to continually improve these processes. The knowledge management model from Argentina can be summarized by the following practices: obtain collective experience from internal sources; acquire information and knowledge from external sources; apply these to procedures; develop future learning innovations; and protect the organization's knowledge assets. The Table 1 shows the requirements related to this item.

Table 1. Management process requirements related to knowledge management based on the model from Argentina.

a) Identify present and future information and knowledge needs in order to develop a business strategy.

b) Guarantee access to information based on external as well as internal sources.

c) Management of the organization, retention, protection and confidentially of information and knowledge.

d) Ensure that information and knowledge are promptly available for those who are responsible for their use. e) Promote organizational knowledge, independently of those who are responsible for their production and administration.

f) Management of networks relationships with external interested parties (such as suppliers, universities) who provide access to knowledge.

g) Evaluate and improve information and knowledge management.

$$
\text { Source: MECA (2013). }
$$

\subsection{Management Excellence Model - Chile}

According to MEMC (2012), the Chilean model is similar to the model from Argentina, in that it provides no specific or fundamental principle related to knowledge management. With regards to its structure of criteria and elements, this model differs from the Argentine model in that it offers separate, but complementary, information and knowledge constructs.

The Chilean model describes the requirements which enable a company to administer information, guaranteeing authenticity and availability, as well as how to manage organizational knowledge. Table 2 shows the requirements related to information management.

Table 2. Management process requirements related to information management outlined in the model from Chile. Adaptations by the authors.

a) Identify information needs to structure daily operations and decision-making.

b) Ensure that the demands of employees, suppliers / partners and clients in identifying information needs are respected.

c) Ensure that information is available to users.

d) Ensure that the technology methods used are secure and easy to use by those who use them.

e) Up-date mechanisms to make available information in accordance with the needs of the business and changes in technology.

f) Guarantee the precision, integrity, reliability, promptness, safety and confidentiality of information.

Source: MEMC (2012).

Table 3. Management process requirements outlined in the Chilean model.

a) Identification, evaluation and management of organizational knowledge to increase the aggregate value of products and services.

b) Maintain organizational knowledge.

c) Collect and transfer knowledge between employees, different areas and teams, clients, suppliers and partners.

d) Manage the exchange and implementation of good practices. 
It is evident that this model focuses on information organization as a way to support the decision-making process, and is concerned with the security and protection of this asset and with the transfer of knowledge, even though no specific mention of a knowledge management base was noted in this model.

\subsection{Model for the Colombian Quality Management Award - Colombia.}

In the case of this model, the management processes relating to knowledge management appears to be linked to an innovation construct, meaning that the organization structures a system of management based on knowledge and organizational learning that directs efforts towards developing new products, services, skills and processes that generate a differential value. The following issues are included in the criteria for the Colombian model: Knowledge Management and Innovation and Methodologies and Innovation Practices, shown in Tables 4 and 5, respectively.

Table 4. Requirements outlined in the model from Colombia for management processes related to knowledge management and innovation.

a) Establish knowledge management as a learning and development factor.

b) Identify, protect and use knowledge as an innovative element for organizational development and to attain a better performance and to create value for the different interested parties.

c) Create knowledge to develop new products, services, processes and skills.

d) Provide incentives to share knowledge, as well as to encourage creative and innovative thinking within the organization.

e) Incorporate experiences and lessons that have been learned as elements that will generate knowledge within the organization

f) Develop areas involving intellectual property rights and copyright.

g) Evaluate and improve knowledge management procedures.

$$
\text { Source: PCC (2014). }
$$

Table 5. Requirements outlined in the model from Colombia referring to methodologies and innovation practices.

a) Present organizational approach for innovation by means of objectives, goals and actions to develop innovation skills.

b) Destination of resources allocated for innovation within an organization.

c) Development of capacities required to create a culture of innovation within an organization. d) Develop innovative procedures, products and services.

e) Share innovative achievements.

f) Evaluate and improve innovation procedures.

Source: PCC (2014).

By adopting an integrated view of knowledge management and innovation, the Colombian model understands that the flow of innovation goes through three stages: a) knowledge administration; b) creating and transferring knowledge; and c) organizational learning. The first stage involves actions to collect, plan, protect, ensure shared use and dissemination of knowledge. The second stage involves focus group sessions, capacity building and training, and the formation of new databases. The final stage involves registering lessons that have been learned and constructing best practice repositories which an organization can use to overcome the challenging situations it may face.

From there, it is possible to establish strategies of innovation, by defining objectives, goals and an organizational and technological structure aimed at constructing news organization skills within the organization. These strategies of innovation should establish the organizational and team skills that deserve to be developed in the short and long terms. Innovation should also be part of the process to protect sensitive information involved in developing new products, services and procedures. And, finally, evaluation mechanisms should be developed for innovation projects which include a system of indicators.

\subsection{Model for National Competitiveness, Medium-size and large Companies - Mexico}

In the case of the Mexican model, the management processes are focused on analyzing how an organization collects, selects, manages and uses data in decision making and to promote innovation at all levels of the organization. Included among the criteria of the Mexican model, are the following elements: Strategy Alignment, Information Management and Knowledge Management, as shown in Tables 6, 7 and 8, respectively.

Table 6. Management process requirements related to strategy alignment included in the Mexican model.

a) Management of information and knowledge systems to support the implementation of an organization's strategic objectives.

b) Identify information and knowledge required to support the implementation of an organization's strategic plan. 
Table 7. Management process requirements related to information management included in the Mexican model.

a) Obtain the necessary information to develop an organization's strategic planning.

b) Manage information to support the implementation of strategic objectives.

c) Manage information to provide guidance for the continual improvement of organizational and process innovation.

d) Information integration for decision making processes at different levels within an organization.

e) Evaluation and improvement of information management processes.

$$
\text { Source: PNC (2013). }
$$

Table 8. Management process requirements related to knowledge management in the Mexican model.

a) Identify an organization's knowledge assets.

b) Structure knowledge to create improvement and innovation projects value.

c) Identify knowledge management improvement projects.

d) Protect organizational knowledge.

e) Evaluate and improve information and knowledge systems.

Source: PNC (2013).

\subsection{Model for Management Excellence in Public Services- Gespública - Brazil}

This is the only model included in the selected sampling that specializes in public sector organizations. According to Gespública (2014), knowledge management is addressed in the Basic principles of Processes and information Guidance and in Information and Knowledge Criteria.

In accordance with these basic principles, the construct of knowledge management is highly correlated to management by processes. The latter has been seen as a set of practical centers of action the purpose of which is to fulfill the objectives of the body and establish decision and control processes grounded information.

On the other hand, the Information and Knowledge criterion of the Gespública model represents information and knowledge management capacity, in particular in relation to implementing management processes that directly contribute towards the systematic selection, collection, storage, use, updating and availability of information that is up-to-date, precise and secure for both internal and external users, taking into account comparative references, strategies and aspects that are relevant to an organization's field of activity. The elements of Information Management and Knowledge Management may be found under this criterion, as shown in Tables 9 and 10, respectively.

Gespública (2014) states that knowledge management advocates the implementation of management processes that aim to identify, develop, manage, protect and share knowledge.

Table 9. Management process requirements related to information management contained in the Brazilian model and applied in the public sector.

a) Identify information needs to support day-to-day operations, accompany progress in the strategic plan and support decision making at all levels.

b) Identify principle information systems and their aims, including the systems of administrative information in public administration.

c) Produce management information, providing the degree of interoperationability between the different information systems and indicators used in information management.

d) Develop and implement improvements in the main information systems.

e) Guarantee the interoperationability between the internal systems of information and public administration administrative systems.

f) Update technology in already developed systems, providing principle technological skills used and policies related to this area.

g) Make available all necessary information to its internal and external public, including users, suppliers and partners.

h) Use information technology to support an organization to fulfill its goals and promote integration between other government organs and with society.

i) Use information management to comply with the Law on Access to Information. .

j) Information security management.

k) Guarantee the updating, confidentiality, integrity and availability of information.

Source: GESPÚBLICA (2014).

Table10. Management process requirements related to knowledge management in the Brazilian model applied to the public sector.

a) Develop and share knowledge within the organization

b) Guarantee that knowledge effectively contributes towards improving procedures, products and services.

c) Protect knowledge and historical information and institutional archives.

d) Identify, develop and measure the organization's intangible assets. 
These two items also help provide guidance to an organization in the identification, development, management, protection and sharing of knowledge.

\subsection{Model of Excellence in Management - FNQ - Brazil}

The Model of Excellence in Management - FNQ is the most useful maturity model in Brazil, in that two of its thirteen basic principles, known as Reasoned Decisions, support management procedures involving knowledge management. A reasoned decision is understood to be a series of resolutions related to directives to be followed and actions to be undertaken, using knowledge created by the treatment of information obtained through measurements, evaluations and performance analysis, risks, feedback and experiences.

According to the Brazilian National Quality Foundation - FNQ (2014), the criterion Information and Knowledge aims to identify information needs and relative treatment so as to define, develop, establish and improve information systems, to integrate organization information with external interested parties and to make this information available while keeping it secure. Thus, the criterion is structured in Organization Information and Organization Knowledge, as shown in Tables 11 and 12, respectively.

Table 11. Management process requirements related to the Brazilian FNQ model of organization information.

a) Identify information needs and their respective treatment, so as to operate and manage an organization.

b) Identify new demands for strategic and operational information.

c) Develop, establish and improve main information systems, taking into consideration the needs that have been identified.

d) Guarantee that up-to-date technology is used in information systems.

e) Ensure there is integration between the organization and its clients, suppliers and other external interested parties, by means of information systems.

f) Create an infrastructure that is compatible with the growth of the business so as to make information available to users.

g) Guarantee users rapid and easy access to information.

h) Guarantee infrastructure continuity, so as to make information available in emergency situations.

i) Evaluate user satisfaction with regards to information and communications systems.

j) Guarantee information security.

k) Ensure that information is updated, and that its confidentiality and integrity is maintained.
Table 12. Management process requirements related to the Brazilian FNQ model for organization knowledge.

a) Identify the most important knowledge needed to fulfil an organization's mission and to implement its strategies.

b) Classify types of knowledge and criteria to define those of greater importance.

c) Provide principal internal and external sources of knowledge that have been used.

d) Develop the most important knowledge.

e) Establish a favorable environment for the search and creation of knowledge.

f) Use personal and organizational networks to help to search for and develop knowledge.

g) Storage knowledge.

h) Adopt methods to attract and retain those persons and partners who hold an organization's most important knowledge.

i) Disseminate and use an organization's knowledge.

j) Provide access to and use knowledge that is held.

k) Share knowledge, both internally and externally.

I) Use personal or organizational networks to help spread knowledge.

Source: FNQ (2014).

According to the FNQ (2014), the relationship between administrative procedures for information and knowledge management includes identifying needs to establishing an information system, and organizational knowledge management, to identifying, developing, retaining and protecting, disseminating and using the knowledge that is necessary to implement strategies.

\subsection{Comparative analysis}

The comparative analysis of models (Table 13) shows that there is a majority group presenting a balanced relationship between categories 1 e 2. That group is compounded by Argentina, Chile, Mexico and Brazil (Gespública). The balanced relationship suggests that organization efforts must be distributed in an equal way, according to these models.

On the other hand, the models from Colombia and Brazil (FNQ) present completely contrary positions. While the Colombia's model is focused in category 2, Brazil's model is focused in category 1 . 
Table 13. Classification of requirements in each Model.

\begin{tabular}{|l|c|c|c|c|}
\hline \multirow{2}{*}{ Model } & \multirow{2}{*}{ Country } & \multicolumn{3}{c|}{ Requeriments } \\
\cline { 3 - 5 } & & Category 1 & Category 2 & Total \\
\hline Model for Management Excellence in Companies & Argentina & $50 \%$ & $50 \%$ & $100 \%$ \\
\hline Management Excellence Model & Chile & $44 \%$ & $56 \%$ & $100 \%$ \\
\hline Model for the Colombian Quality Management Award & Colombia & $0 \%$ & $100 \%$ & $100 \%$ \\
\hline $\begin{array}{l}\text { Model for National Competitiveness, Medium-size and large } \\
\text { Companies }\end{array}$ & Mexico & $48 \%$ & $52 \%$ & $100 \%$ \\
\hline $\begin{array}{l}\text { Model for Management Excellence in Public Services - } \\
\text { Gespública }\end{array}$ & Brazil & $73 \%$ & $27 \%$ & $100 \%$ \\
\hline Model of Excellence in Management (FNQ) & Brazil & $51 \%$ & $49 \%$ & $100 \%$ \\
\hline
\end{tabular}

Source: Made by Authors.

Table 14. Presence of elements of Knowledge Management in each Model.

\begin{tabular}{|l|c|c|c|c|c|c|c|}
\hline \multirow{2}{*}{ Model } & \multirow{2}{*}{ Country } & \multicolumn{6}{c|}{ Activities } \\
\cline { 3 - 8 } & & Sharing & Creating & Applying & Storing & Identification & Total \\
\hline $\begin{array}{l}\text { Model for Management Excellence } \\
\text { in Companies }\end{array}$ & Argentina & $43 \%$ & $14 \%$ & $14 \%$ & $14 \%$ & $14 \%$ & $100 \%$ \\
\hline Management Excellence Model & Chile & $30 \%$ & $0 \%$ & $20 \%$ & $30 \%$ & $20 \%$ & $100 \%$ \\
\hline $\begin{array}{l}\text { Model for the Colombian Quality } \\
\text { Management Award }\end{array}$ & Colombia & $12 \%$ & $35 \%$ & $29 \%$ & $18 \%$ & $6 \%$ & $100 \%$ \\
\hline $\begin{array}{l}\text { Model for National } \\
\text { Competitiveness, Medium-size and } \\
\text { large Companies }\end{array}$ & Mexico & $0 \%$ & $0 \%$ & $58 \%$ & $8 \%$ & $33 \%$ & $100 \%$ \\
\hline $\begin{array}{l}\text { Model for Management Excellence } \\
\text { in Public Services- Gespública }\end{array}$ & Brazil & $31 \%$ & $6 \%$ & $25 \%$ & $19 \%$ & $19 \%$ & $100 \%$ \\
\hline $\begin{array}{l}\text { Model of Excellence in } \\
\text { Management (FNO) }\end{array}$ & Brazil & $35 \%$ & $13 \%$ & $13 \%$ & $22 \%$ & $17 \%$ & $100 \%$ \\
\hline
\end{tabular}

Source: Made by Authors.

In a second analysis was identified the presence of the activities of knowledge management such as the definition used on this paper. Each process requirement was classified according the activity most closely with. The result is presented on Table 14.

The models from Argentina, Chile and Brazil (Gespúplica and $\mathrm{FNQ}$ ) are focused on sharing activity while the models from Colombia and Mexico are focused on creating and applying activities respectively.

\section{CONCLUSIONS}

The Latin American models of Management Excellence present different levels of structure and maturity. The most mature, such as the model from Colombia, treat a knowledge management construct as being part of strategic perspectives, information management and innovation management. Few research studies were found that treated knowledge management as being inseparable from innovation, as seen in the work by Bukowitz (2002) who explicitly approaches innovation as a dependent variable of knowledge management. According to Heisig (2009), innovation appears within the activity to generate knowledge.

Another lacuna found in some of the Latin American models of excellence, was the absence of knowledge management as a fundamental organizational structure. Despite the models from Argentina, Chile, Mexico and Brazil (Gespública) presented a balanced relationship between categories 1 and 2. There are other world class models, such as the Malcolm Baldrige National Quality Award and the European Foundation for Quality Management Award.

For the effect of comparing findings, another international point of reference, the model from Singapore, treats knowledge management as being the central core of an organization, aligning the organization's operation with its strategic objectives. Two items may be observed in the Criterion Information: a) Information and Knowledge Management; and b) Comparison and Benchmarking. 
Brazilian Journal of Operations \& Production Management Volume 13, Número 2, 2016, pp. 150-158

DOI: 10.14488/BJOPM.2016.v13.n2.a2
According to the SQA (2014), requisites for these three elements stipulate that a systematized analysis of knowledge management should be carried out, observing: performance measurements; the use of comparative data to establish an organization's situation in relation to its competitors; organizational performance evaluations; availability of information technology; and the continual search for innovation.

With regards to Latin America, and the demand to seek innovation and the constant need to adopt external comparative references in order to measure performance, the Brazilian Gespública (2014) and the FNQ (2014) models deserve to be highlighted in particular.

For future studies are suggested the deepening of the relationship between knowledge management and innovation and the correct balancing between requirements classified how category 1 and 2 .

The present research study makes it possible to provide consistent and normalized analyses based on pre-existing models that view knowledge management as a fundamental part of an organization. It is suggested that a future research agenda should consider the need to extend this study to include other Latin American countries.

\section{REFERENCES}

Bardin, L. (2002). Análise de Conteúdo. Lisboa: Edições 70.

Barclay, R. O., \& Murray, P. C. (1997). What is knowledge management. A Knowledge praxis.

Broadbent, M. (1997). The emerging phenomenon of knowledge management. The Australian library journal, 46(1), 6-24.

Bukowitz, R. W. \& WILLIAMS, L. R. (2002). Como utilizar o manual de gestão do conhecimento. In: . Manual de gestão do conhecimento. Porto Alegre: Bookman.

Dalkir, K. (2005). Knowledge Management in Theory and Practice. New York: Butterworth-Heinemann.

Davenport, T. H., De Long, D. W., \& Beers, M. C. (1998). Successful knowledge management projects. Sloan management review, 39(2), 43-57.

Earl, M. J., \& Scott, J. A. (1999). Opinion: what is a chief knowledge officer? Sloan management review, 40, 29-38.

FNQ (2014). Fundação Nacional da Qualidade. Critérios de Avaliação 2014, São Paulo.

FNQ (2007). Fundação Nacional da Qualidade. Edições Temáticas: Capital Intelectual e Inovação - A gestão dos Intangíveis, São Paulo.
Gespública (2014). Brasil. Ministério do Planejamento, Orçamento e Gestão. Instrumento para a Avaliação da Gestão Pública - Ciclo 2014. Brasília: Seges.

MECA (2013). Model for Management Excellence in Companies - Argentina. Critérios de Avaliação 2014, Buenos Aires.

MEMC (2012). Management Excellence Model - Chile. Critérios de Avaliação 2012, Santiago.

Nonaka, I. (2008). A empresa criadora do conhecimento. In, Nonaka, I. \& Hirotaka, T. 2008. Gestão do conhecimento. Porto Alegre, RS: Bookman.

Heisig, P. (2009). Harmonisation of knowledge management-comparing $160 \mathrm{KM}$ frameworks around the globe. Journal of Knowledge Management, 13(4), 4-31.

Hood, C. (1991). A public management for all seasons? Public administration, 69(1), 3-19..

Sveiby, K. E. (2014). What is knowledge management? Disponível em http://www.sveiby.com/articles/ KnowledgeManagement.html. Acessado em 15 de dezembro de 2014. 